\title{
Early recognition and rapid intervention of sepsis: I mplementation of a focused educational initiative emphasizing early goal-directed therapy in the emergency department
}

\author{
Hope Moser \\ Houston Methodist Hospital, Houston Methodist Hospital System Biomedical Ethics Program, Houston, TX, USA. \\ Correspondence: Hope Moser. Address: 6411 Fannin, 6 Robertson 6.677, Houston, TX 77030, USA. Email: \\ hope.moser@memorialhermann.org
}

Received: January 27, 2014

Accepted: March 28, 2014

Online Published: April 10, 2014

DOI : 10.5430/jnep.v4n6p23

URL: http://dx.doi.org/10.5430/jnep.v4n6p23

\section{Abstract}

Introduction: Prompt recognition of Systemic Inflammatory Response Syndrome (SIRS)/sepsis and early initiation of goal-directed therapy in the emergency department is vital for improved patient outcomes. The aim of this educational initiative was to implement an educational program detailing the imperative steps within the "golden hour" of early recognition and intervention of SIRS/sepsis in the emergency department and analyze the effectiveness of the intervention.

Methodology: This performance improvement project was the program evaluation of a mandatory educational initiative, incorporating a retrospective, repeated measures, test-retest, time series design for registered nurses working in the emergency department who were specifically trained in the emergency department triage $(n=38)$, at an emergency department between January 2008-March 2008.

Conclusions/Significance: Results of the statistical analysis showed a positive change between pre-test (t1) and initial post-test ( $\mathrm{t} 2)$ scores, ( $\mathrm{t} 1$ and $\mathrm{t} 2) p=.000,(95 \% \mathrm{CI}-5.072,-3.402)$, indicating understanding of the educational material provided and between (t1) and one-month post-test (t3) scores, ( $\mathrm{t} 1$ and $\mathrm{t} 3) \mathrm{p}=.0001,(95 \% \mathrm{CI}-5.345,-3.780$ ), showing retention of the educational material. The educational initiative implemented in the emergency department was beneficial in educating the nurses and resulted in practice change at the facility. As a result, the educational initiative was implemented as a house-wide annual nursing competency. The initiative was instrumental in the development of a house-wide interprofessional, collaborative sepsis task force.

\section{Key words}

Systemic Inflammatory Response Syndrome/SIRS, Sepsis, Septic shock, Severe Sepsis, Surviving Sepsis Guidelines

\section{Introduction}

While programs aimed at early goal-directed treatment of stroke is increasingly common in the inpatient setting, most emergency department settings continue to lack the necessary tools to standardize a protocol ${ }^{[1]}$. Elderly patients do not always present with a classic set of symptoms. It is imperative that the emergency department triage nurse receives 
detailed, content specific education to identify patients at highest risk for the most time-sensitive conditions, such as sepsis.

In one private, adult, teaching hospital, approximately $70 \%$ of patients who met the criteria of severe sepsis/septic shock were admitted to the hospital from the emergency department. A retrospective chart review of patients treated with sepsis at the institution over a five-month period from August 2008-January 2009 revealed fifty-one patients presented to the emergency department and were admitted to an inpatient acute care unit with confirmed severe sepsis/septic shock. Additionally, the rapid response team identified several "failure to rescue" incidents in patients originating in the emergency department that were transferred to an acute care unit and were ultimately diagnosed with severe sepsis/septic shock (personal communication, 2008).

The published studies on SIRS/sepsis and early goal-directed therapy are cohesive and while the literature supports specific positive outcomes on initiating early goal-directed therapy in the emergency department, there are limited published educational initiatives focused on the front-line triage nurses. The aim of this educational initiative was to implement and analyze the effectiveness of an educational initiative detailing the imperative steps within the "golden hour" of early recognition and intervention of sepsis in the emergency department.

\subsection{Review of the literature}

Sepsis is associated with substantial mortality and consumption of health care resources. With a mortality rate of up to $54 \%$ annually, severe sepsis remains a significant healthcare burden ${ }^{[1]}$. With the majority of severe sepsis patients receiving initial treatments in the emergency department (ED), it is important for ED personnel to rapidly assess and recognize SIRS/spies in order for patients to receive early goal-directed therapy which has become the standard-of-care across all healthcare departments and facilities ${ }^{[2,3]}$. Several studies demonstrate improved patient outcomes when initial interventions are administered within the first six hours of care. Further emphasizing the importance of timely and organized intervention, care administered during the first hour, often termed the "golden hour" is associated with improved patient outcomes ${ }^{[4]}$.

There are global deficiencies in early recognition and rapid intervention of sepsis in emergency departments. Appropriate triage and identification of patients presenting with SIRS/sepsis within the first 1 to 6 hours has not been performed effectively or consistently ${ }^{[5]}$. There is disagreement throughout multidisciplinary healthcare teams when discussing sepsis treatment. Nguyen et al. ${ }^{[1]}$ attributes the lack of cohesiveness to the lack of healthcare provider education on sepsis, minimal physician buy-in related to the current trends surrounding early goal-directed therapy, lack of appropriate and available ICU beds, as well as various administrative obstacles.

Systemic Inflammatory Response Syndrome (SIRS) is defined as a clinical response to a nonspecific insult of either infectious or noninfectious origin. SIRS criteria is met when 2 or more of the following clinical manifestations occur: fever of more than $38^{\circ} \mathrm{C}\left(100.4^{\circ} \mathrm{F}\right)$ or less than $36^{\circ} \mathrm{C}\left(96.8^{\circ} \mathrm{F}\right)$; heart rate of more than 90 beats per minute; respiratory rate of more than 20 breaths per minute or arterial carbon dioxide tension $\left(\mathrm{PaCO}_{2}\right)$ of less than $32 \mathrm{~mm} \mathrm{Hg}$; and abnormal white blood cell count $\left(>12,000 / \mu \mathrm{L}\right.$ or $<4,000 / \mu \mathrm{L}$ or $>10 \%$ immature [band] forms ${ }^{[6]}$.

Sepsis is a clinical syndrome that complicates severe infection and is characterized by systemic inflammation and widespread tissue injury. Severe sepsis is defined as sepsis plus at least one sign of organ hypoperfusion. Early clinical manifestations of tissue hypoperfusion are hypotension, tachycardia, oliguria, altered mental status, serum lactic acidosis, and hypoxia ${ }^{[4]}$. Septic shock often results due to microcirculatory alterations despite adequate fluid resuscitation and maintenance of adequate perfusion pressures ${ }^{[4]}$.Multiple organ dysfunction syndrome is likely to develop if both macro and microcirculatory functioning is not restored early ${ }^{[7,8]}$. The physiologic foundation for minimum $\mathrm{StO}_{2}$ (tissue oxygenation) rests on the theory that peripheral hypoperfusion is a marker for a worsening patient condition as it coincides with the body's shunting of blood to the internal organs and away from the periphery ${ }^{[9]}$. The hallmark of multiple organ dysfunction syndrome is the development of progressive physiologic dysfunction in two or more organ systems after an 
acute threat to systemic homeostasis, with the respiratory, renal, hepatic, cardiovascular, and hematologic systems being most commonly affected ${ }^{[7]}$.

\subsection{The guidelines}

Early recognition and rapid intervention of sepsis is crucial to the overall course of treatment as well as sepsis related mortality ${ }^{[4]}$. The Institute for Healthcare Improvement (IHI) and the Surviving Sepsis Campaign (SSC) provide management guidelines surrounding treatment of SIRS/sepsis with the ultimate goal to prevent sepsis and septic shock ${ }^{[10]}$. The SSC and IHI recommend implementation of a six-hour resuscitation bundle, specifically intended to be expeditiously initiated in the emergency department. The resuscitation bundle incorporates early recognition, immediate fluid resuscitation, early cultures, and expedited antibiotic administration as the framework for early goal-directed therapy $(\text { EGDT })^{[10]}$

Current SSC protocols for EGDT are written as protocolized resuscitation formats, also known as "severe sepsis bundles". Sepsis bundles should be initiated when sepsis is suspected ${ }^{[6]}$. Since the completion of this performance improvement project, there has been an update to the Surviving Sepsis Campaign in 2012.

\subsection{Resuscitation goals}

During the first six hours of resuscitation, the goals of initial resuscitation of severe sepsis-induced hypoperfusion should include all of the following as part one of the treatment protocol: central venous pressure (CVP) 8-12mmHg; mean arterial pressure (MAP) $\geq 65 \mathrm{mmHg}$; urine output $\geq 0.5 \mathrm{ml} / \mathrm{kg}^{-1} / \mathrm{hr}^{-1}$; central venous (superior vena cava) or mixed venous oxygen saturation $\geq 70 \%$ or $\geq 65 \%$, respectively ${ }^{[6]}$. Early goal-directed resuscitation has been shown to improve survival for emergency department patients presenting with septic shock ${ }^{[11]}$.

\section{Materials}

IRB approval for the protection of human subjects was granted. Verbal consent was obtained from each registered nurse prior to each pre-test and educational presentation.

This doctoral capstone (Doctor of Nursing Practice, DNP), is a program evaluation of a mandatory educational initiative targeting registered nurses working in the role of emergency department triage. As previously stated, the majority of patients admitted with sepsis presented through the emergency department. Methods incorporated a retrospective chart review of 51 patients diagnosed with sepsis to serve as a needs assessment to determine a gap analysis. Incidentally, the most common chief complaint from the 51 patients admitted with SIRS/sepsis was altered mental status. At the time of this performance improvement initiative, altered mental status was not included in SIRS criteria. Since the completion of this project, it is recognized that there has been updated Surviving Sepsis Guidelines with the inclusion of altered mental status to the diagnostic criteria for sepsis ${ }^{[12]}$. The education intervention and testing tool validated at the time of the program intervention would not have been changed in light of these updates.

A repeated measures, time series, test-retest design was used for the evaluation of the triage nurses working in the emergency department $(n=38)$, between January 2008-March 2008 .

The educational pre-test, post-test, and intervention was content focused and concentrated on pathophysiologic review of the current SIRS/sepsis criteria; importance of early recognition of symptoms- specifically, the SIRS criteria; characteristics associated with atypical presentation of sepsis; the emergency department policy for sepsis screening that was in use at the time; and the step by step, protocolized resuscitation bundle that was recommended to be started within the first 6 hours of symptom recognition as mandated by the Surviving Sepsis Guidelines. The intervention developed for this program is offered as a house-wide annual competency surrounding early recognition and intervention of sepsis for acute care registered nurses. 
Figure 1. Pre/Post Test Questions

\section{Pre/Post Test Questions}

1. The following are possible signs of early sepsis:

a. Temperature $>100.4^{\circ} \mathrm{F}\left(38^{\circ} \mathrm{C}\right)$ or $<96.8^{\circ} \mathrm{F}\left(36^{\circ} \mathrm{C}\right)$

b. Heart Rate $>90 \mathrm{bpm}$ (tachycardia)

c. Respiratory Rate $>20$ (Tachypnea) or $\mathrm{PaCO} 2<32 \mathrm{mmHg}$

d. $\mathrm{WBC}>12,000$ or $<4,000$ or $>10 \%$ bands

e. All of the above

2. As sepsis progresses, one can expect to see:

a. Hypotension

b. Hypoxia

c. Altered Mental Status

d. Decreased Urine Output

e. All of the above

3. A patient with altered mental status should be considered for sepsis screening. TRUE FALSE

4. Assuming you are following protocol with physician orders included and the patient has a patent central line IV, the most important intervention to immediately initiate after recognizing a septic patient is:

a. Fluid Resuscitation

b. Draw 2 sets of blood cultures

c. Place Foley Catheter

d. Start broad spectrum antibiotics

5. The hallmark of severe sepsis is impaired tissue perfusion secondary to:

a. Tachycardia

b. Tachypnea

c. Arterial Hypotension

d. Oliguria

6. Broad spectrum antibiotics should be started after cultures are drawn and within the first 6 hours of sepsis recognition TRUE FALSE

7. In early sepsis, you would expect the skin of the patient to be:

a. Cold and mottled

b. Cool and clammy

c. Pink and warm

d. Dusky and clammy

8. Volume resuscitation is the most important intervention before antibiotics.

TRUE FALSE

9. When evaluating the effects of fluid resuscitation, the fluid challenge should be titrated to: (Chose all that apply).

a. Urine output

b. Skin turgor

c. Heart rate

d. Blood pressure

10. If fluid resuscitation alone is insufficient to restore hemodynamic stability, the nurse would anticipate starting:

a. Norepinephrine

b. Dopamine

c. Amikacin

d. Dobutamine

11. In the TMH ED, a SIRS score of $>2$ would trigger the notification of the ED MD.

TRUE FALSE

12. Septic shock is: (Chose all that apply)

a. Sepsis with hypotension not improved by fluid resuscitation

b. Evidence of hypoperfusion (AMS, renal dysfunction)

c. Clinical suspicion of infection

d. Inability to access port-a-cath

13. A temperature of $<36^{\circ} \mathrm{C}\left(96.8^{\circ} \mathrm{F}\right)$ is as critical as being febrile.

TRUE

FALSE

14. A clinical sign of impending respiratory failure is:

a. Tachypnea

b. Bradycardia

c. Bradypnea

d. Tachycardia

15. The RN in the ED triage area has the most important role in recognizing the patient who is at risk for severe sepsis. TRUE

FALSE 


\subsection{Demographics}

There were 53 registered nurses employed in the emergency department. Of those, 38 registered nurses were trained in the role of triage. Thirty-six of the thirty-eight nurses were employed full-time and thirty two had earned a baccalaureate degree and six had earned a master's degree.

Table 1. Emergency Room Registered Nurse Demographics

\begin{tabular}{lllllllllll}
\hline $\begin{array}{l}\text { Total } \\
\text { RN }\end{array}$ & $\begin{array}{l}\text { Total RN } \\
\text { Triage }\end{array}$ & $\begin{array}{l}\text { FT ED } \\
\text { RN }\end{array}$ & $\begin{array}{l}\text { PT ED } \\
\text { RN }\end{array}$ & $\begin{array}{l}\text { FT ED RN } \\
\text { Triage }\end{array}$ & $\begin{array}{l}\text { PT ED RN } \\
\text { Triage }\end{array}$ & BSN & $\begin{array}{l}\text { BSN } \\
\text { Triage }\end{array}$ & MSN & $\begin{array}{l}\text { MSN } \\
\text { Triage }\end{array}$ & $\begin{array}{l}\text { Female } \\
(\%)\end{array}$ \\
\hline 53 & 38 & 43 & 10 & 36 & 2 & 45 & 32 & 8 & 6 & $80 \%$ \\
\hline
\end{tabular}

$\mathrm{N}$ of population demographics. Gender described as percent.

\subsection{Statistical analysis}

A two-tailed paired t-test was selected to compare the same sample before and after the intervention.

Table 2. Paired Samples Statistics (t1) and (t2), (t1) and (t3)

\begin{tabular}{|c|c|c|c|c|c|}
\hline & & Mean & $\mathbf{N}$ & SD & Std. Error Mean \\
\hline \multirow{2}{*}{ Pair 1} & t 1 score & 9.32 & 38 & 1.974 & 0.320 \\
\hline & t 2 score & 13.55 & 38 & 1.132 & 0.184 \\
\hline \multirow{2}{*}{ Pair 1} & t 1 score & 9.28 & 32 & 1.853 & 0.325 \\
\hline & t 3 score & 13.84 & 32 & 1.051 & 0.186 \\
\hline
\end{tabular}

A two-tailed paired t-test was performed comparing test scores at $(\mathrm{t} 1)(\mathrm{n}=38$, mean 9.32, SD 1.974) and ( $\mathrm{t} 2)(\mathrm{n}=38$, mean 13.55, SD 1.132) showing a significant positive difference between ( $\mathrm{t} 1$ and $\mathrm{t} 2) \mathrm{p}=.0001$, (95\% CI $-5.072,-3.402)$, indicating understanding of the educational information presented.

Table 3. Paired Samples Statistics (t1) and (t2), (t1) and (t3)

\begin{tabular}{|c|c|c|c|c|c|c|c|c|c|}
\hline & & \multicolumn{8}{|c|}{ Paired Differences } \\
\hline & & \multirow{2}{*}{ Mean } & \multirow{2}{*}{ SD } & \multirow{2}{*}{ Std. Error Mean } & \multicolumn{2}{|c|}{ 95\% Confidence Interval } & \multirow{2}{*}{$\boldsymbol{t}$} & \multirow{2}{*}{ df } & \multirow{2}{*}{$p$} \\
\hline & & & & & Lower & Upper & & & \\
\hline Pair 1 & $\begin{array}{l}\text { t } 1 \text { score } \\
\text { t } 2 \text { score }\end{array}$ & -4.237 & 2.541 & .412 & -5.072 & -3.402 & -10.279 & 37 & .0001 \\
\hline Pair 1 & $\begin{array}{l}\text { t } 1 \text { score } \\
\text { t } 3 \text { score }\end{array}$ & -4.563 & 2.169 & .383 & -5.345 & -3.780 & -11.898 & 31 & .0001 \\
\hline
\end{tabular}

A two-tailed paired t-test was performed comparing test scores at $(\mathrm{t} 1)(\mathrm{n}=32$, mean 9.28, SD 1.853) and $(\mathrm{t} 3)(\mathrm{n}=32$, mean 13.84, SD 1.051) showing a significant positive difference between ( $\mathrm{t} 1$ and $\mathrm{t} 3) \mathrm{p}=.0001,(95 \% \mathrm{CI}-5.345,-3.780)$, indicating retention of information presented during the educational presentation.

\section{Discussion}

Implementation of this educational initiative for registered nurses trained in emergency triage was beneficial in educating the nurses. The statistical analysis supports a significant increase between pre-test ( $\mathrm{t} 1$ ) and the initial post-test scores ( $\mathrm{t} 2$ ), indicating understanding of the information provided in the educational session and a positive statistically significant change between ( $\mathrm{t} 1$ ) and the 1-month post-test ( $\mathrm{t} 3$ ), indicating retention of the educational program information. Commonly, the lowest acceptable retention rate in a behavioral study is $70 \%$ to maintain study validity ${ }^{[13]}$.

To sustain positive program impact, several efforts continue to maximize participation in educational initiatives. 
While the educational initiative was effective in improving knowledge for the emergency department triage nurses, implementation of the program was not without limitations. Loss to attrition ( $n=38$ at $t 1$ to $n=32$ at $t 3)$ is explained by employment change, inability to contact a participant, military obligations and the unfortunate and untimely death of one of the nurses.

Since the completion of this performance improvement initiative, the sepsis education tool developed in this program was implemented as a mandatory, annual competency for all inpatient, acute care registered nurses.

Since the conclusion of this performance improvement project, the need for SIRS/sepsis focused education for all inpatient acute care nurses was demonstrated. Due to the high acuity of patients admitted to nursing units, the sepsis education developed in this program was implemented as a mandatory, annual competency for all inpatient, acute care registered nurses.

\section{Conclusion}

Sepsis remains a leading cause of death worldwide and the need for continued SIRS/sepsis education for nurses is imperative. Incorporating education with focused SIRS/sepsis screening of the highest patients at risk is included in the next phase of the hospital wide initiative.

\section{References}

[1] Nguyen HB, Corbett SW, Steele R, Banta J, Clark RT, Hayes SR, Edwards J, Cho TW, Whittlake WA. Implementation of a bundle of quality indicators for the early management of severe sepsis and septic shock is associated with decreased mortality. Critical Care Medicine. 2007; 35(4): 1105-1112. PMid:17334251 http://dx.doi.org/10.1097/01.CCM.0000259463.33848.3D

[2] Talan DA, Moran GJ, Abrahamian FM. Severe sepsis and septic shock in the emergency department. Infectious Disease Clinics of North America. 2008; 22: 1-31. PMid:18295681 http://dx.doi.org/10.1016/j.idc.2007.09.005

[3] Shoor AF, Micek ST, Jackson WL, Kollef MH. Economic implications of an evidence-based sepsis protocol: Can we improve outcomes and lower costs? Critical Care Medicine. 2007; 35(5): 1257-1262. PMid:17414080 http://dx.doi.org/10.1097/01.CCM.0000261886.65063.CC

[4] Nguyen HB, Rivers EP, Abrahamian FM, Moran GJ, Abraham E, Trzeciak S, Huang DT, Osborn T, Stevens D, Talan DA. Severe sepsis and septic shock: Review of the literature and emergency department management guidelines. Annals of Emergency Medicine. 2006; 48(1): 28-53. PMid:16781920 http://dx.doi.org/10.1016/j.annemergmed.2006.02.015

[5] Shapiro NI, Howell MD, Talmor D, Lahey D, Ngo L, Buras J, Wolfe RE, Woodrow-Weiss J, Lisbon A. Implementation and outcomes of the Multiple Urgent Sepsis Therapies (MUST) protocol. Critical Care Medicine. 2006; 34(4): 1025-1032. PMid:16484890 http://dx.doi.org/10.1097/01.CCM.0000206104.18647.A8

[6] Dellinger RP, Levy MM, Carlet JM, Bion J, Parker MM, Jaeschke R. Surviving Sepsis Campaign: International guidelines for management of severe sepsis and septic shock. Critical Care Medicine. 2008; 36(1): 296-327. PMid:18158437 http://dx.doi.org/10.1097/01.CCM.0000298158.12101.41

[7] Marshall JC, Cook DJ, Christou NV, Bernard GR, Sprung CL, Sibbald WJ. Multiple Organ Dysfunction Score: A reliable descriptor of a complex clinical outcome. Critical Care Medicine. 1995; 23(10): 1638-1652. PMid:7587228 http://dx.doi.org/10.1097/00003246-199510000-00007

[8] Moore FA, Sauaia A, Moore EE, Haenel JB, Burch JM, Lezotte DC. Postinjury multiple organ failure: A bimodal phenomenon. The Journal of Trauma, Injury, Infection, and Critical Care. 1996; 40(4): 501-512. http://dx.doi.org/10.1097/00005373-199604000-00001

[9] Cohen SM, Nathens AB, Moore FA, Rhee P, Puyana JC, Moore EE, Beilman GJ. Tissue oxygen saturation predicts the development of organ dysfunction during traumatic shock resuscitation. The Journal of Trauma Injury, Infection, and Critical Care. 2007; 62: 44-55. PMid:17215732 http://dx.doi.org/10.1097/TA.0b013e31802eb817

[10] Clemmer TP, Dellinger RP, Resar RK, Townsend S. Implementing the surviving sepsis campaign. 2005; Available from: http://ssc.sccm.org/files/Implementing\%20the\%20Surviving\%20Sepsis\%20Campaign.pdf on November 29, 2008. 
[11] Rivers E, Nguyen B, Havstad S, Reesler J, Muzzin A, Knoblich B, Peterson E, Tomlanovich M. for the Early Goal-Directed Therapy Collaborative Group. Early goal-directed therapy in the treatment of severe sepsis and septic shock. New England Journal of Medicine. 2001; 345(19): 1368-1377. PMid:11794169 http://dx.doi.org/10.1056/NEJMoa010307

[12] Dellinger RP, Levy MM, Rhodes A, Djillali A, Gerlach H, Opal SM, et al. Surviving Sepsis Campaign: International guidelines for the management of severe sepsis and septic shock: 2012. Critical Care Medicine. 2013; 41(2): 580-637. PMid:23353941 http://dx.doi.org/10.1097/CCM.0b013e31827e83af

[13] Bruzzese JM, Gallahher R, McCann-Doyle S, Reiss PT, Wuetunga NA. Effective methods to improve recruitment and retention in school-based substance use prevention studies. Journal of School Health. 2009; 79(9). PMid:19691714 http://dx.doi.org/10.1111/j.1746-1561.2009.00427.x 